\title{
Process Design for Hybrid Sheet Metal Components
}

\author{
Rico Haase $^{1} \cdot$ Roland Müller $^{1} \cdot$ Dirk Landgrebe $^{1} \cdot$ Peter Scholz $^{1} \cdot$ Matthias Riemer $^{1}$
}

Received: 30 June 2015/Revised: 18 November 2015/Published online: 12 December 2015

(C) The Chinese Society for Metals and Springer-Verlag Berlin Heidelberg 2015

\begin{abstract}
The global trends towards improving fuel efficiency and reducing $\mathrm{CO}_{2}$ emissions are the key drivers for lightweight solutions. In sheet metal processing, this can be achieved by the use of materials with a supreme strength-toweight and stiffness-to-weight ratio. Besides monolithic materials such as high-strength or light metals, in particular metalplastic composite sheets are able to provide outstanding mechanical properties. Thus, the adaption of conventional, wellestablished forming methods for the processing of hybrid sheet metals is a current challenge for the sheet metal working industry. In this work, the planning phase for a conventional sheet metal forming process is studied aiming at the forming of metal-plastic composite sheets. The single process steps like material characterization, FE analysis, tool design and development of robust process parameters are studied in detail and adapted to the specific properties of metal-plastic composites. In material characterization, the model of the hybrid laminate needs to represent not only the mechanical properties of the individual combined materials, but also needs to reflect the behaviour of the interface zone between them. Based on experience, there is a strong dependency on temperature as well as strain rate. While monolithic materials show a moderate anisotropic behaviour, loads on laminates in different directions generate different strain states and completely different failure modes. During the FE analysis, thermo-mechanic and thermo-dynamic effects influence the temperature distribution within tool and work pieces and subsequently the forming behaviour. During try out and production phase, those additional influencing factors are limiting the process window even more and therefore need to be considered for the design of a robust forming process. A roadmap for sheet metal forming adjusted to metal-plastic composites is presented in this paper.
\end{abstract}

KEY WORDS: Characterization; Hybrids; Interface; Layered structures; Processing; Sheet forming

\section{Introduction}

Lightweight solutions have attained a top priority within the field of sheet metal forming [1]. Beside strategies of system and function integration, especially an optimized

Available online at http://link.springer.com/journal/40195

Rico Haase

rico.haase@iwu.fraunhofer.de

1 Fraunhofer Institute for Machine Tools and Forming Technology IWU, Reichenhainer Strasse 88, 09126 Chemnitz, Germany material distribution is able to provide improvements in strength and stiffness of sheet metal components. Commonly, those components are subjected to a complex set of different loads. Following a load-oriented design approach [2], those complex loads are decomposed into basic load cases, such as tensile and bending loads. Based on those isolated requirements, necessary layer composition and thickness proportions can be derived.

For different applications and use cases, there is a broad variety of different material combinations and thickness proportions available. Thick polymeric cores are used to generate a high bending inertia, while thin, shear-deformable cores are used for damping purposes and applications of 


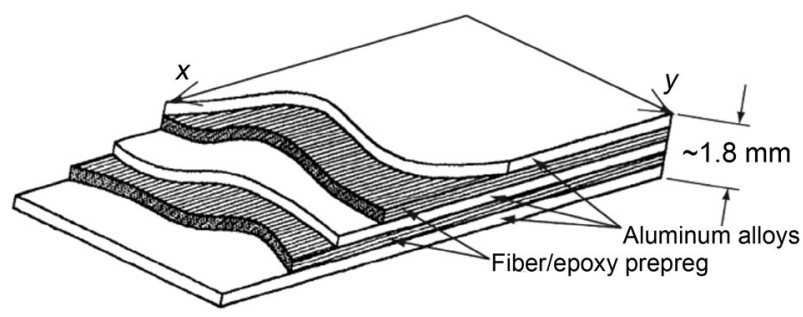

Fig. 1 Layered material Glare with fibre reinforcement in multiple directions [8]

acoustic impact [3]. To realize a cost-effective manufacturing of metal-polymer composite sheets in a large-scale production, the use of conventional sheet metal forming process chains is intended. However, the specific layout of the laminate layers leads to additional aspects and criteria for

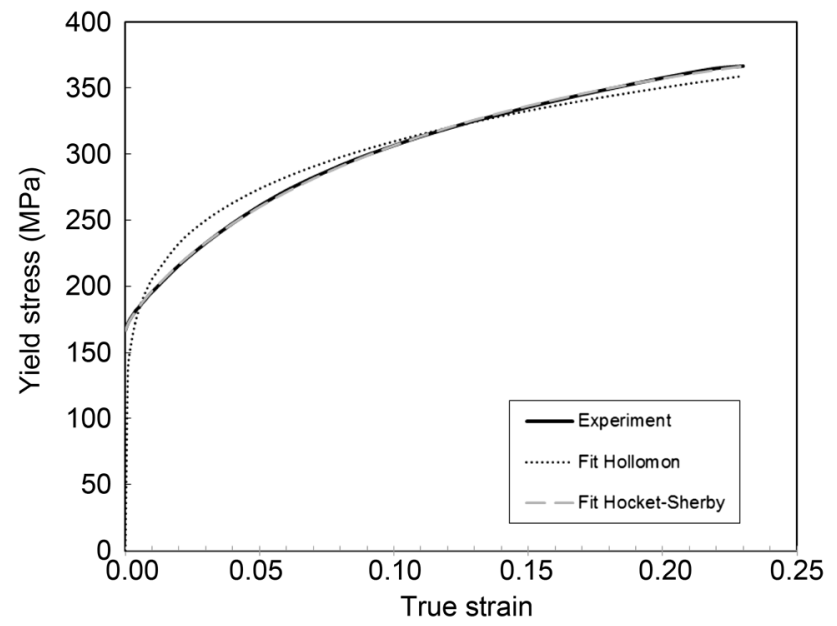

Fig. 2 Experimental data from tensile test of a 0.58-mm DX54 and fitted analytical descriptions

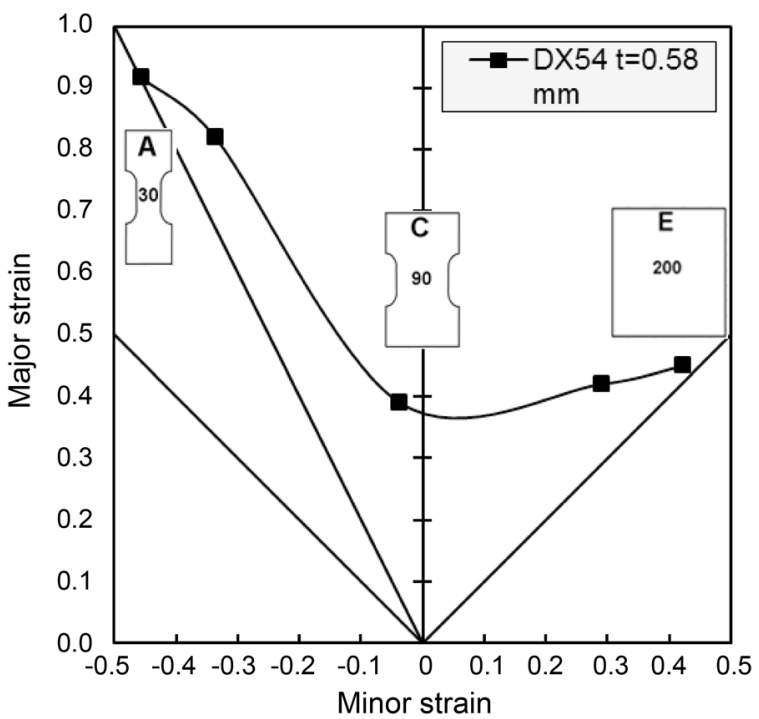

Fig. 3 Forming limit curve (FLC) of a 0.58-mm DX54 steel sheet, geometries of specimens are sketched into the diagram

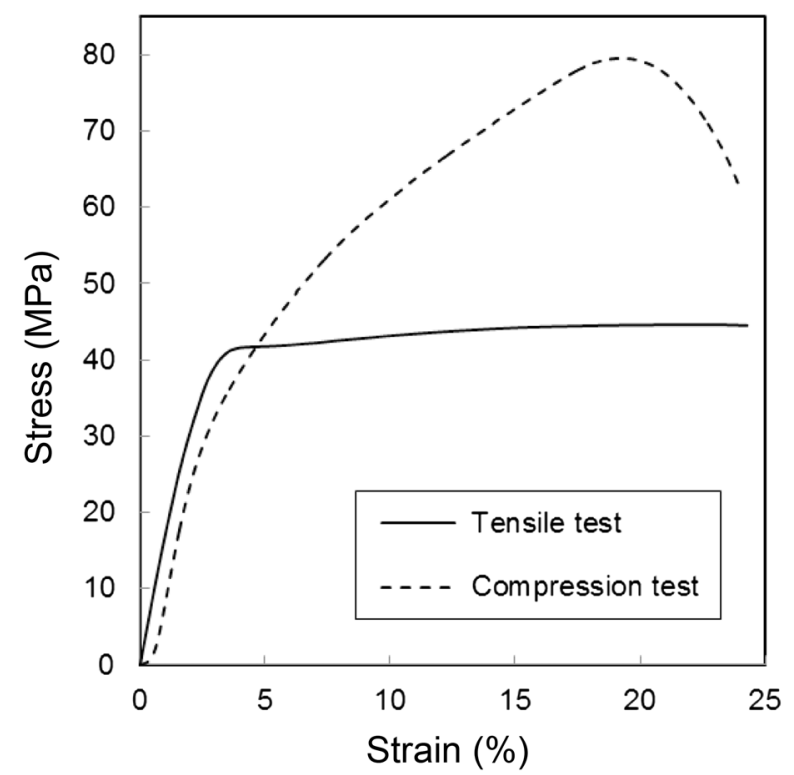

Fig. 4 Absolute stress value depending on tensile and compression strain for PA6 material under room temperature and $45 \%$ moisture

the development and the evaluation of the forming processes. For example, the lower strength and stiffness of the polymeric layer lead to new failure modes such as wrinkling of the metal skin layers into the core material [4].

In the field of shell-typed components and bending beams, the bending forces are clearly dominating over the small portion of pure tensile loads. This implies that a high level of bending inertia is required. The most efficient way to achieve this is to increase the thickness of the hybrid material and thus the distance between the neutral elastic line and the elongated/compressed outer layers [5]. As elongation is distributed unevenly across the sheet thickness, a laminate structure evolves. The typical metal-plastic-metal structure results from the positioning of a material with a high strength and stiffness on the outmost positions of the layer composition. In the less stressed and strained core area, a material with lower mechanical properties but also lower density can be used as interlayer. Common layer thicknesses of hybrid pre-materials are $t=0.2-0.25 \mathrm{~mm}$ for the metallic cover shells and $t=0.4-1.0 \mathrm{~mm}$ for the polymeric interlayer [6] which can be fibre-reinforced to a certain amount of about $25 \%-90 \%$. Although the overall thickness varies between different suppliers and products on the market, the thickness of the core layer commonly exceeds the thickness of the cover sheets by a factor of $2-5$ and even above.

In the field of bending beams, the material Hylite ${ }^{\circledR}$ (brand of 3A composites) shows a typical layer composition [7]. In the particular case, the cover sheets are made from a $t=0.2 \mathrm{~mm}$ EN AW-5182 (AlMg4.5Mn0.4) aluminium with a polypropylene core in either $t=0.8 \mathrm{~mm}$ or $t=1.6 \mathrm{~mm}$ thickness. The core to cover thickness ratio is 4 or 8 accordingly. 
In the field of tensile beams, the situation is quite vice versa. In this use case, the position of the particular laminate component within the material thickness is not of significant importance. Thus, fibre reinforcements usually are situated in the middle layer of the laminate. Long fibre reinforcements are able to provide a much higher level of elastic and plastic properties than short fibre reinforcements. But this uniform orientation also results in a strong anisotropic behaviour. Consequently, different orientations of the reinforcement fibres are necessary to correlate with the applied loads. The different alignments can be combined in one or even several plastic layers.

Figure 1 shows the material Glare, which is a typical example of such a multi-layer composition. Glass fibres are used for reinforcement, while the metal layers are made of aluminium. Due to the multiple fibre layers, a quasi-isotropic behaviour can be achieved. Beside stiffness, lightweight and damping performance, especially the impact behaviour and latency of crack growth are the key drivers for aeronautical applications [8].

A further approach is the use of shear-deformable polymeric interlayers for damping purposes. By separation of the single metallic layers by plastic (e.g. polymeric) interlayers, any orthogonal displacement of the laminate generates a shear deformation within the more flexible plastic shell. By energy dissipation, the movement of the whole structure is damped. Also an array of interlayers is common, e.g. for minimizing the sound level passing through the laminate or for reducing the noise radiation from a large surface structure. The Fraunhofer IWU is currently participating in a publicly funded corporate research project to reduce structure-borne noise by a customized core layer design and composition [9].

\section{Process Planning for Processing of Hybrid Sheet Metals}

\subsection{Material Characterization}

Starting point for the characterization of the hybrid material usually is the characterization of the single components. For the metallic cover sheets, there are several well-established material characterization routines defined which are available both on a scientific and on an industrial scale. Beside tensile tests utilized to determine Young's modulus, yield and tensile strength, also more sophisticated material characterization techniques such as maxi bulge test, Nakajima test and biaxial tension test are available at IWU [10]. Those allow to exceed the limited strain level from uniaxial tests and furthermore the application of biaxial strains. The measurement results are used as input for the material model in FEA. The approximation of the flow curve by an analytical rule ensures a continuous dependency of strength and strain, as shown in Fig. 2. The fitting of the analytic parameters to the measured pairs of variates is done by the method of least squares.

The possible strain until failure in sheet metal forming commonly is described by the forming limit curve (FLC) which reflects the possible strain values until local necking and crack [11], as shown in Fig. 3. To achieve different strain proportions, specimens of different widths are subjected to a Nakajima test. The intermediate values are added by an interpolated curve.

Due to the orderless microstructure of the plastic/polymeric interlayers [12], a quasi-isotropic behaviour can be attributed. Anyhow, the organic material comes up with a few specifics such as strong dependency on moisture content, temperature and strain rate. Because of the polymeric structure, the behaviour under elongation and compression conditions is not symmetrical, as shown in Fig. 4. Although the absolute strength values reduce at elevated temperature, they show the same behaviour and similar relations. Regarding those restrictions, the material properties are elaborated with similar testing devices and procedures as the metal sheets [10]. To cover the broad variety of temperature/moisture/strain rate-combinations, an array of test cycles is required. The quantity can be slightly reduced by means of DoE.

During the recent years, more and more attention is attracted by the interface between the single laminate layers [13]. To achieve a clear understanding of binding principles and interaction with the manufacturing

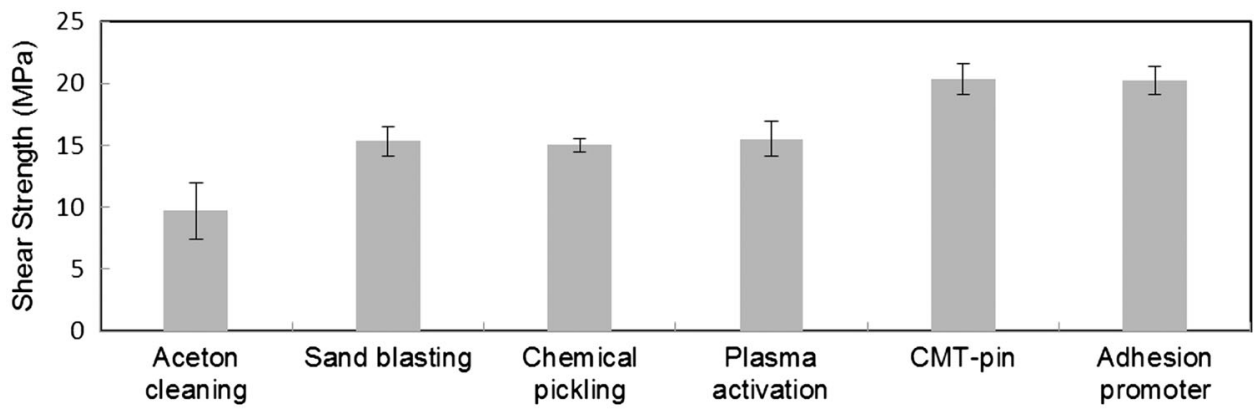

Fig. 5 Shear strength dependent on different types of surface treatment [15] 


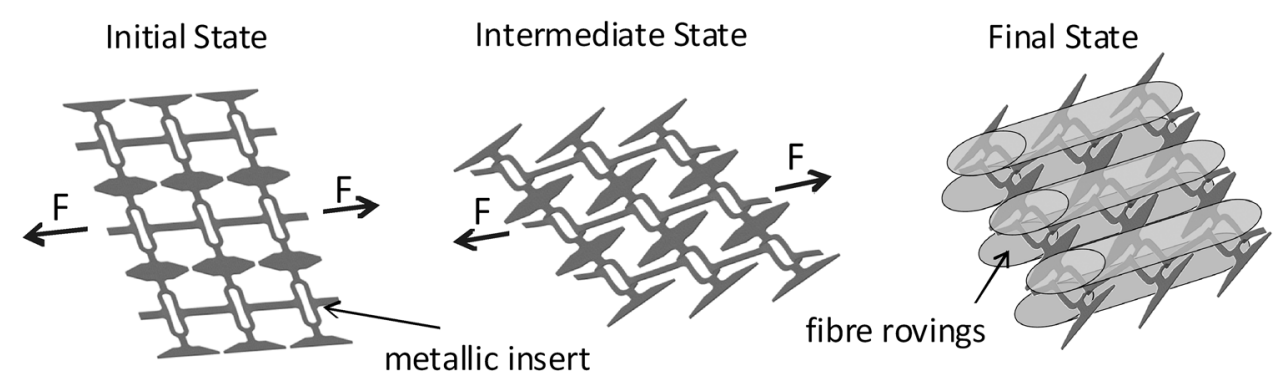

Fig. 6 Sketch of mechanical interlocks by out-of-plane deformation of metal core layer with designed trim line shape

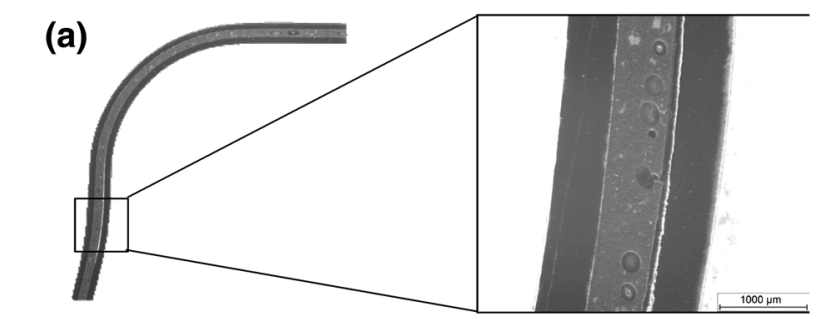

(b)

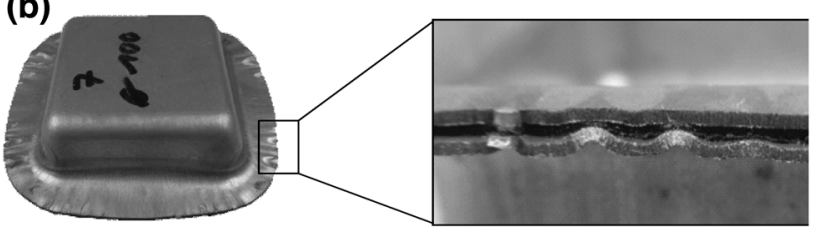

Fig. 7 a Delamination of a metal-polymer-metal laminate at the layer interface after bending; $\mathbf{b}$ wrinkling of cover sheets into the core material in the flange area of a deep drawn square cup

processes, the inspection in different scale levels is mandatory. On the microscale, adhesion is the dominating mechanism, while on both the meso- and macroscales, cottering and mechanical interlocks are also important. Derived from this conclusion, there is a variety of different surface treatments which can be used to influence and improve the layer bonding, such as degreasing (e.g. acetone cleaning); mechanical treatment (e.g. sand blasting, grinding, polishing, engraving); chemical treatment (e.g. chemical pickling, adhesion promoter); electrolytic treatment (e.g. electrolytic polishing) and CMT pins. By the different surface conditions, different properties of the interface and subsequently of the whole laminate can be adjusted [14]. A highly anisotropic behaviour in normal and tangential direction is observed in any case. The aimed properties commonly are: shear strength, tensile strength in normal direction, steady fracture behaviour and decreased velocity of damage growth.

To quantify the shear and tensile strengths of a bonded laminate, shear and tensile test specimens are loaded in a tensile test machine. An example for the shear strength dependency on surface treatment of the metal cover sheets is given in Fig. 5 [15]. In this particular case, the combination of 1.4301 stainless steel cover sheets towards a CFK-reinforced core layer was characterized.

Currently, basic mechanisms for cottering and mechanical interlocks on a macroscale are developed at Fraunhofer IWU within the DFG SPP1712 'Intrinsic hybrid composites for lightweight construction structures'. The intrinsic approach is aiming at an establishment of the layer bonding during or even through the forming process [16]. As illustrated in Fig. 6, there is an out-of-plane deformation induced by the elongation of the metallic layer. By the distinctive shape of the cutting lines in the sheet metal, a torsion moment is induced which moves mechanical interlocks into the fibre-reinforced plastic matrix.

\subsection{Process Routes}

Following the ongoing demand for lightweight solutions, the initial intention of the sheet metal working industry was to replace monolithic blanks by hybrid laminates without changing the equipment and the process strategies. Due to

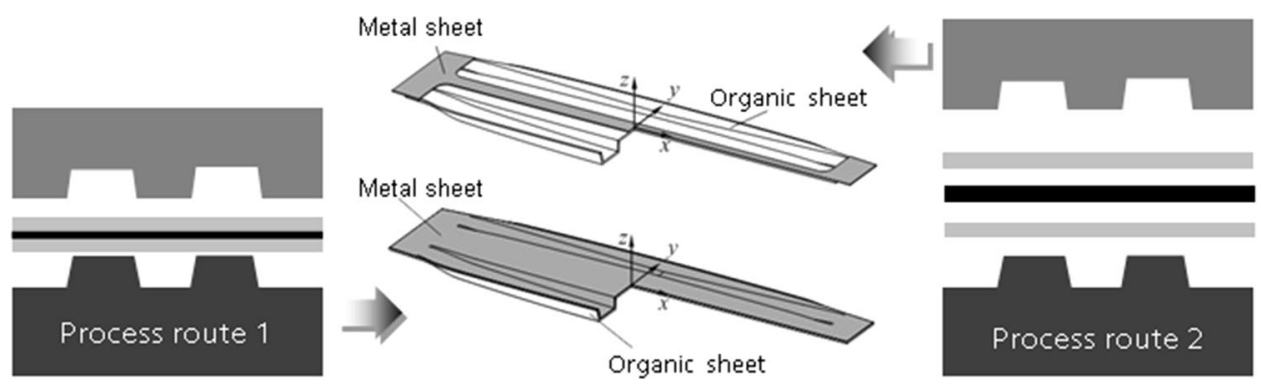

Fig. 8 Schematic representation of manufacturing strategies, the bonding process can be operated before, after or during forming process 
Table 1 Comparison of possible process routes and key advantages and disadvantages

\begin{tabular}{|c|c|c|c|}
\hline $\begin{array}{l}\text { Manufacturing } \\
\text { strategy }\end{array}$ & Process route & Advantages & Disadvantages \\
\hline $\begin{array}{l}\text { Laminate bond } \\
\text { established before } \\
\text { forming operation }\end{array}$ & $\begin{array}{l}\text { Hybrid sheets used as pre- } \\
\text { material }\end{array}$ & $\begin{array}{l}\text { Process quite similar to conventional (monolithic) sheet } \\
\text { metal forming; no bonding process of single } \\
\text { components needs to be considered }\end{array}$ & Lowest formability limit \\
\hline $\begin{array}{l}\text { Laminate bond } \\
\text { established after } \\
\text { forming operation }\end{array}$ & $\begin{array}{l}\text { Metallic and organic sheets } \\
\text { are formed in the same or } \\
\text { separate mould }\end{array}$ & $\begin{array}{l}\text { High formability limit, as sliding of loose layers is } \\
\text { possible }\end{array}$ & $\begin{array}{l}\text { Bonding needs to be } \\
\text { performed in a separate } \\
\text { process step }\end{array}$ \\
\hline $\begin{array}{l}\text { Laminate bond } \\
\text { established during } \\
\text { forming operation }\end{array}$ & $\begin{array}{l}\text { Metallic and organic sheets } \\
\text { are assembled in mould }\end{array}$ & $\begin{array}{l}\text { High formability limit; forming tool can be used for } \\
\text { shaping and clamping during bonding }\end{array}$ & $\begin{array}{l}\text { Highest cycle time due to } \\
\text { heating and cooling of die } \\
\text { and component }\end{array}$ \\
\hline
\end{tabular}

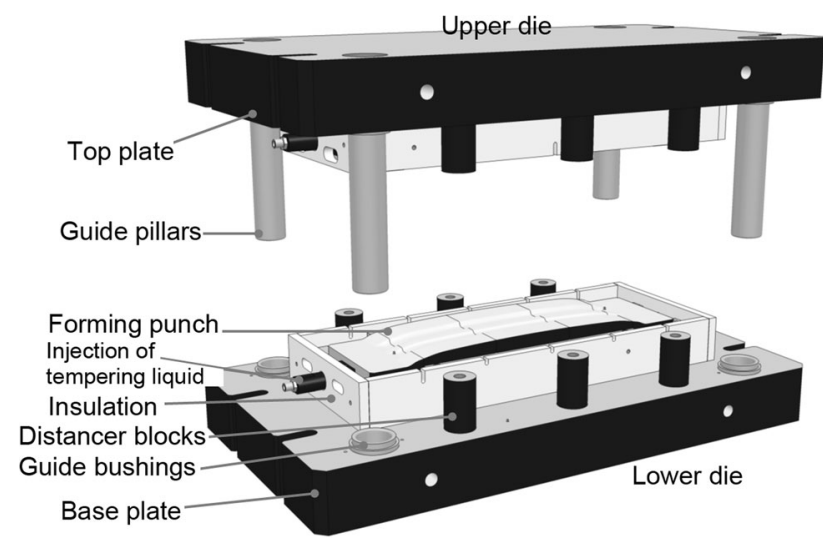

Fig. 9 Schematic diagram of tempered forming tool

the slightly increased material thickness and inhomogeneous properties across the layers, a changed material forming behaviour is observed. This also includes a couple of failure modes which appear under bending or deep drawing conditions: delamination under shear stress (Fig. 7a) and wrinkling into the core material under compression conditions (Fig. 7b). Furthermore, extended lateral pressure leads to thinning of the polymeric core layer. Increased temperature levels even intensify this effect up to squeezing out of core material.

Beside the quantification of formability level of the hybrid laminate in own and various other works, the IWU works on a DFG-AiF funded cluster project 'Process chains for complex parts made of hybrid laminates' [17]. The central idea of this project is to analyse, categorize and benchmark different process strategies for the manufacturing of hybrid laminate components. One of the core questions is, by when the laminate layers are bonded together-before, after or even during the forming process (Fig. 8), the advantages and disadvantages of the different layouts are listed in Table 1.

The complexity of the intended component and the required output of the manufacturing line were figured out as the two key factors for the implementation of hybrid sheet forming processes into an automotive application scenario. Thus, a more reliable forecast on achievable stroke rates and output volumes for tempered tooling equipment is mandatorily required to implement the technology on an industrial scale.

\section{Experimental Set-up and Benchmark of Process Routes}

In order to quantify the process parameters such as temperature levels, heating and cooling rates, cycle times, press force and process robustness, an automotive component was selected for benchmarking of the different manufacturing strategies. A tempered forming die (Fig. 9)

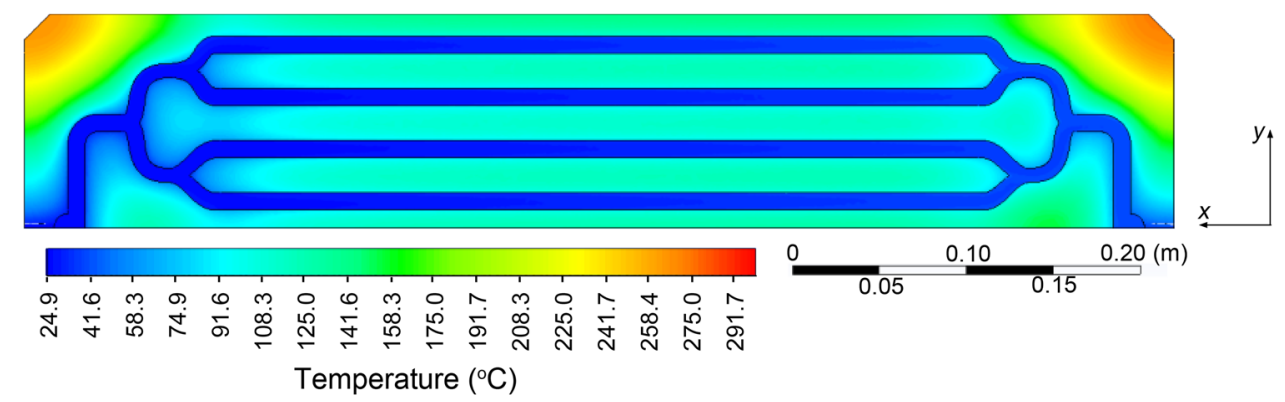

Fig. 10 Temperature field on actively liquid-tempered die after 300-s cooling time (half model) [18] 


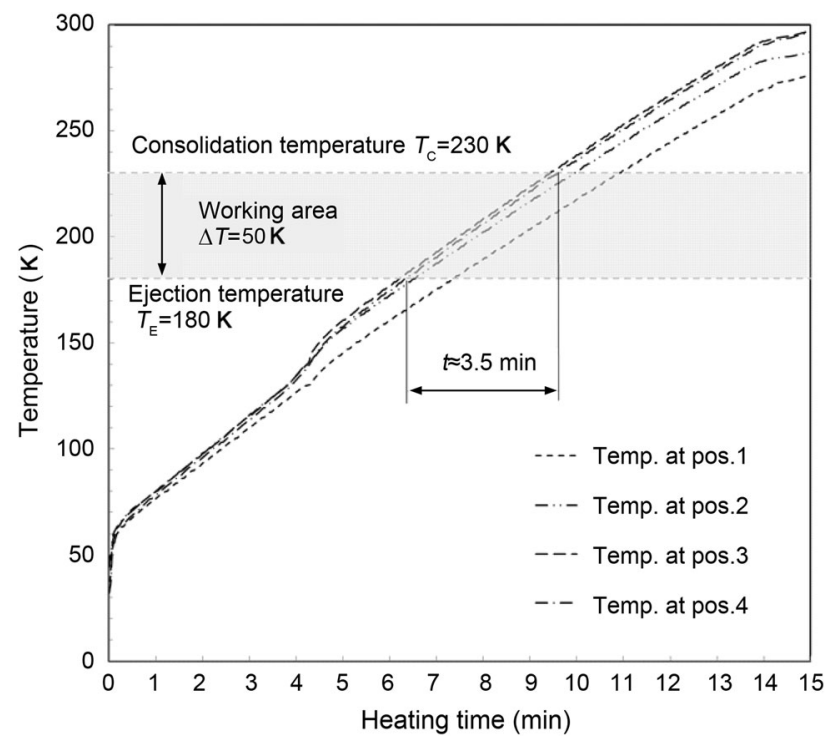

Fig. 11 Temperature behaviour of closed tool and clamped part during heating

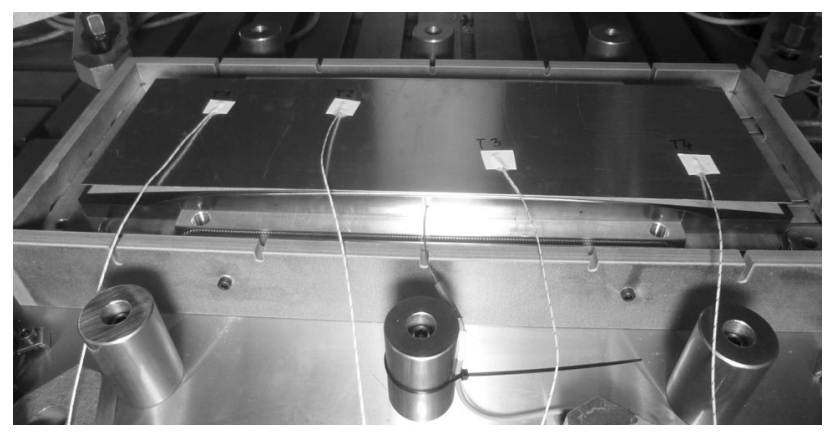

Fig. 12 Position of temperature sensors on part surface

was designed and manufactured aiming towards a wide temperature range to cover a variety of different polymeric core materials.

Following the demand of reduced cycle times, the aim was to realize a cooling from $T=300{ }^{\circ} \mathrm{C}$ to a value below $T=180{ }^{\circ} \mathrm{C}$ within $<300 \mathrm{~s}$. In the coupled fluid-dynamic and thermal FE analysis, different tempering media and geometries of the cooling channel were benchmarked. Finally, a bionic-like channel layout and water as cooling media performed best [18]. As described in Fig. 10, the temperature has dropped even below $T=125^{\circ} \mathrm{C}$ within the given time frame. Dividing the temperature drop of approx. $\Delta T=100 \mathrm{~K}$ within $300 \mathrm{~s}$, a mean cooling rate of $\Delta T / t=0.33 \mathrm{~K} / \mathrm{s}$ was achieved.

For a complete production cycle, the tool needs to be reheated up to the consolidation temperature level again. For this purpose, conventional electric heating cartridges were used. Lower and upper dies were heated by electric power of $P=4.5 \mathrm{~kW}$ each. The according mean heating rate $\Delta T / t$ is $50 \mathrm{~K} / 210 \mathrm{~s} \approx 0.25 \mathrm{~K} / \mathrm{s} \quad$ (Fig. 11). Figure 10 shows nearly linear temperature behaviour within the working range. In Fig. 12, the positions of the different temperature sensors on the part surface are illustrated. Taking the temperature range of $\Delta T=50 \mathrm{~K}$ and the mean heating and cooling rates into account, there are time periods of $t=150 \mathrm{~s}$ for cooling and $t=200 \mathrm{~s}$ for heating required. With an additional time span of $t=40 \mathrm{~s}$ for press stroke and handling, a cycle time of $t=6.5 \mathrm{~min}$ can be achieved.

A topic for further research is the increase in heating and cooling rates. Beside higher power input for heating and cooling, especially the temperature distributions within the tool as well as within the part have to be taken into account. For this purpose, the approach of part-integrated sensor functionality [19] is an important measure for a controlled process.

\section{Summary}

Initially, the characterization of single components as well as the whole laminated structure has been discussed. Based on the inhomogeneous forming behaviour, specific failure modes have been identified and forming limits derived. The comparison of different manufacturing strategies raised the demand for an improved tempering of the forming tools. A rapid conditioning of a demonstrator die could be shown within experiments.

Acknowledgments The authors cordially wish to thank the German Research Foundation (DFG), German Federation of Industrial Research Associations (AiF) and the European Research Association for Sheet Metal Working (EFB) for their support and respective funding in the research projects this article is based on. The project 'Process chains for complex parts made of hybrid laminates' is funded by the AiF via EFB under Grant No. 17690 BR/1. The project 'Intrinsic hybrid composites for lightweight construction structures' is funded by the DFG under Grant No. SPP 1712. The project 'Reduction of noise radiation by damping in hybrid laminates' is funded by the AiF via EFB under Grant No. 17895 BG.

\section{References}

[1] M. Kleiner, M. Geiger, A. Klaus, CIRP Ann. Manuf. Technol. 52, 521 (2003)

[2] F. Schieck, R. Haase, K. Richter, T. Lehnert, N. Pierschel, Paper Present in Proceedings 4th International Lower Silesia-Saxony Conference on Advanced Metal Forming Processes in Automotive Industry Auto Met Form in association with 21st Saxon Conference on Forming Technology SFU, ed. by R. Kawalla. TU Bergakademie Freiberg (2014)

[3] D. Pieronek, T. Böger, R. Röttger, Paper present in the LSDyna-Forum 2012, Ulm, 9 Oct. (2012)

[4] R. Neugebauer, S. Scheffler, Schaffung Umformtechnischer Grundlagen bei der Verarbeitung von Metall-Kunststoff-Verbunden (European Research Association for Sheet Metal Working EFB, Hannover, 2009) 
[5] M. Weiß, B.F. Rolfe, M.E. Dingle, P.D. Hodgson, Steel Grips 2, 445 (2004)

[6] J. Kraus, Thyssen-Krupp Steel Europe baut Produktionsanlage für steifigkeitsoptimiertes Material (MM Maschinenmarkt, 2011), http://www.maschinenmarkt.vogel.de/themenkanaele/ konstruktion/werkstoffe/articles/301085/. Accessed 1 Sept 2015

[7] A Composites GmbH, HYLITE ${ }^{\circledR}$ (3A Composites, 2015), http:// www.transport-industry.com/products/hylite/product-properties. html. Accessed 15 April 2015

[8] E.C. Bothelo, R.A. Silva, L.C. Pardini, M.C. Rezende, Mater. Res. 9, 247 (2006)

[9] European Research Association for Sheet Metal Working (EFB), Reduktion der Schallabstrahlung durch gezielte Schubdämpfung in hybriden Metall-Kunststoff-Verbunden. Project Profile (Chemnitz/Hanover, 2015), http://www.efb.de/-forschung/ laufendeprojekte/laufendeprojekte.html. Accessed 24 June 2015

[10] R. Neugebauer, R. Müller, Material Testing and Characterization, http://www.iwu.fraunhofer.de/content/dam/iwu/en/documents/ Brochures/IWU-KB-Material-Testing-and-Characterization.pdf. Accessed 24 June 2015

[11] R. Müller, M. Riemer et al., Resolution Requirements in Timedependent FLC Testing. Paper presented in the International Deep Draw Research Group (IDDRG) Conference 2015, Shanghai, 1-3 June 2015

[12] H. Domininghaus, Kunststoffe (Springer, Heidelberg, 2012), p. 37
[13] D. Nestler, Habilitation, Beitrag zum Thema Verbundwerkstoffe und Werkstoffverbunde: Status quo und Forschungsansätze, (Technische Universität Chemnitz, 2014) pp. 209-210

[14] T. Osiecky, H. Seidlitz, C. Gerstenberger, L. Kroll, P. Scholz, Paper Present in Proceedings 4th International Lower SilesiaSaxony Conference on Advanded Metal Forming Processes in Automotive Industry AutoMetForm in association with $21^{\text {st }}$ Saxon Conference on Forming Technology SFU, ed. by R. Kawalla. TU Bergakademie Freiberg (2014)

[15] A. Hälsig, A. Podlesak, F. Mayr, M. Trautmann, C. Döhler, D. Nestler, B. Wielage, Verbundwerkstoffe: 19. Symposium Verbundwerkstoffe und Werkstoffverbunde, eds. by A. Wanner, K. A. Weidenmann, (2013) pp. 500-509

[16] German Research Foundation (DFG), SPP 1712, Intrinsic Hybrid Composites for Lightweight Construction StructuresBasics of Manufacturing, Characterisation and Mechanical Design, http://gepris.dfg.de/gepris/projekt/255883585, http:// www.spp-1712-hybrider-leichtbau.de/, Accessed 25th June 2015

[17] P. Scholz et al., Umformprozessketten für Bauteile aus FaserKunststoff/Metall-Verbunden, paper presented at the 35. EFBKolloquium Blechverarbeitung, Bad Boll, 24-25 March 2015

[18] S. Melzer, Master thesis, Technische Universität Chemnitz, 2015

[19] R. Neugebauer, L. Lachmann, W.G. Drossel, M. Nestler, S. Hensel, Prod. Eng. Res. Dev. 4, 379 (2010) 